\title{
Research and Optimization on Ticket Vending Machine Based on Human-computer Interaction
}

\author{
Yan Zhou and Siyu Wang \\ School of Mechatronic Engineering, Harbin Institute of Technology, Harbin, China
}

\begin{abstract}
This paper makes the subway automatic ticket machine as the research subject, presents the suggestion of conducting the research and optimization based on human-computer interaction. We establish evaluation model of user experience based on the survey, correlation analysis and factor analysis. Selecting the representative TVM scheme and quantize the indicators based on the evaluation model, the best scheme with the highest degree of user experience will be selected. Furthermore, this paper establishes and standardizes the evaluation element index matrix by using the Analytic Hierarchy Process(AHP)-Grey Relational Analysis(GRA) and compute the comprehensive correlation degree to determine the best solution. The TVM differences between China and Japan are analyzed based on the calculation results, and the suggestion on the user experience improvement is put forward.
\end{abstract}

Keywords-component; human-computer interaction; user experience; Ticket Vending Machine (TVM); AHP-grey relational analysis

\section{INTRODUCTION}

The urban rail transit has so many advantages such as large traffic volume, safety and environmental protection, timeliness and speed etc. Currently, the urban rail transit systems have been constructed in more than 10 metropolises like Beijing, Tianjin etc., and there are still other urban rail transit systems under construction in other 33 cities. [1] Along with the increasingly expanded rail transit routes, the requirement on metro service facilities are also improved gradually. As the very important equipment in auto ticketing and check-in system, the Ticket Vending Machine (TVM) can realize the freedom degree and convenience of passenger's ticketing, reduce plenty of manpower consumption caused by manual ticketing and improve the overall quality of railway service accordingly [2].

Currently, the analysis and improvement on TVM are mainly concentrated in system development and module technological upgrading. There is still a lack of analysis and research on the whole set of ticketing service process in the aspect of humancomputer interaction. [3] In this paper, it takes the TVMs in Beijing and Japan as the representative, to quantify the user's subjective experience and emotion volume while using the ticketing service, to establish the TVM usability evaluation model based on human-computer interaction from the interactive and visual aspects. Then based on the confirmed usability evaluation elements to make the analysis and comparison, then to get the difference in usability accordingly. Further to summarize the optimized design scheme and provide the guidance for TVM design accordingly.

\section{THE ESTABLISHMENT OF TVM EVALUATION MODEL}

\section{A. The Extraction of TVM User Experience Elements}

The main purpose of the improvement in human-computer interaction quality shall be to improve the efficiency and increase customer satisfaction, the concrete manifestations shall be to improve user's experiencing degree, helping the user achieve the target even faster and reduce user's chance of making mistakes. Peter Morville has refined the target of user experience, proposed the user experience honeycomb and those key points of usability, accessibility, reliability, availability, satisfaction degree and value property etc. [4]. By combining the interactive characteristics of TVM, to analyze the key elements of TVM user experience from the visual, interactive, ticketing procedure, information construction, technical support aspects etc., and establish the evaluation model as per shown in Fig. I.

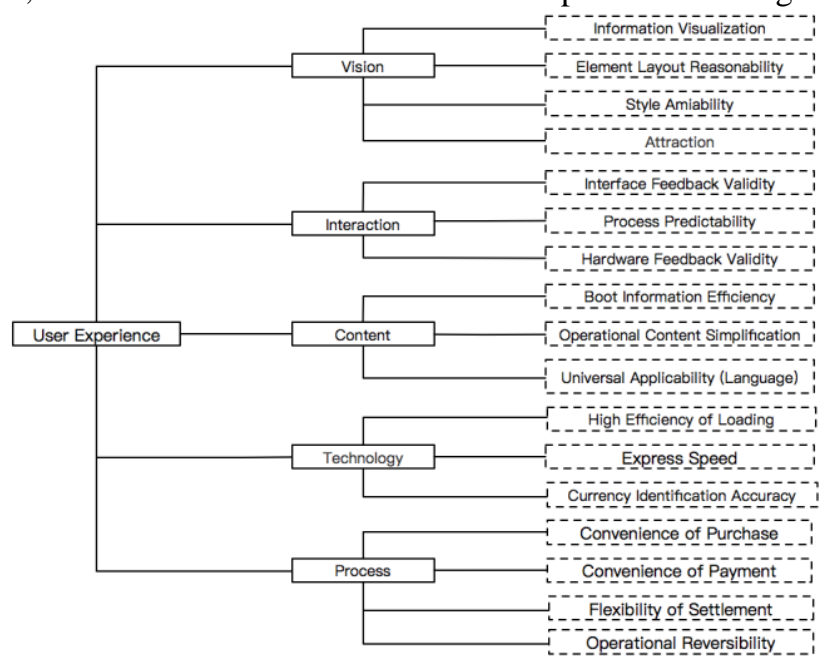

FIGURE I. TVm USER EXPERIENCE EVALUATION MODEL.

\section{B. The Reliability Analysis on Evaluation Element Data}

In order to verify whether the usability evaluation model is reasonable and effective, the questionnaire Likert five-point scale statistics was used for testing the reliability of results. Through the test, the visual element' s Cronbach's alpha ( a ) coefficient was 0.774 , and the $\alpha$ value of other variables were both larger than 0.8 , it has the high degree of internal consistency and dependability, and also the quite good reliability. In validity test, KMO's value was larger than 0.5, Bartlett sphere test statistical value was less than 0.001 , it then proved that the validity $\mathrm{p}$ was quite good and fit for factor analysis. In this study, the KMO value of each variable was both larger than 0.5 , Bart1ett sphere test statistical value $\mathrm{p}=0.000$.

On above basis, in this paper the correlation analysis was made on each evaluation index and its matching dimension, the 
overall evaluation of each dimension and user experience. The acquired analysis shows that the correlation coefficient between the general usability and content elements was 0.665 , just located between 0.4 and 0.7 , it shall be moderately correlated; and the correlation coefficient between each remained evaluation index and its matching dimension were both bigger than 0.7 , it shall be intensively correlated, it then showed that each evaluation index in the model can be used to measure its matching dimension. Besides, the correlation analysis shows that there shall be moderate correlation between the interactive elements and overall evaluation of user experience, there are the intensive correlation between visual element, content element, technical element, ticketing procedure and the overall evaluation of user experience, it then showed that the TVM usability can be evaluated from above five dimensions.

\section{Exploratory Factor Analysis on Evaluation Element Data}

In order to verify whether the number of influencing factors on observation variable was in consistent with the set figure, the observation variables were screened to determine the measurement model. In this paper the exploratory factor analysis was carried out accordingly. The KMO value of overall variables was 0.889 , Bartlett sphere test statistical value $\mathrm{p}=0.000$, it met the condition to carry out factor analysis. Through the factor analysis on each variable in the study model of this paper, it then extracted 5 factors, the accumulative contribution rate of these 5 factors was $61.809 \%$, higher than $50 \%$, and meeting the requirement. Through the factor transposition with maximum variance orthogonal rotation method, the acquired rotation factor matrix result showed that the factor analysis can identify the five facets of user experience, and the distribution of the measurement index in the five facets was basically reasonable. Among the measurement indexes a load of a reversible factor was less than 0.5 , according to the requirement of factor analysis on factor load, such index should be eliminated accordingly. After eliminating the reversibility, to repeat the factor analysis again, the attractive factor's load was less than 0.5 , after eliminating the attractive force to repeat the factor analysis once again, the acquired result was shown in Table I.

TABLE I. ROTATIONAL COMPONENT MATRIX

\begin{tabular}{|l|c|c|c|c|c|}
\hline \multirow{2}{*}{ Element } & \multicolumn{5}{|c|}{ Component } \\
\cline { 2 - 6 } & $\mathbf{1}$ & $\mathbf{2}$ & $\mathbf{3}$ & $\mathbf{4}$ & $\mathbf{5}$ \\
\hline Information Visualization & .147 & .064 & .197 & .694 & .028 \\
\hline $\begin{array}{l}\text { Element Layout } \\
\text { Reasonability }\end{array}$ & .197 & .164 & .119 & .768 & .066 \\
\hline Style Amiability & .212 & .071 & -.014 & .715 & .116 \\
\hline Interface Feedback Validity & .176 & .181 & .718 & .181 & .092 \\
\hline Process Predictability & .146 & .272 & .769 & .049 & .191 \\
\hline Hardware Feedback Validity & .273 & .217 & .652 & .158 & -.01 \\
\hline Boot Information Efficiency & .647 & .242 & .150 & .240 & .254 \\
\hline $\begin{array}{l}\text { Operational Content } \\
\text { Simplification }\end{array}$ & .659 & .245 & .199 & .268 & .165 \\
\hline $\begin{array}{l}\text { Universal Applicability } \\
\text { Language) }\end{array}$ & .693 & .283 & .133 & .232 & .138 \\
\hline High Efficiency of Loading & .133 & .630 & .386 & .110 & .125 \\
\hline Express Speed & .232 & .695 & .291 & .032 & .048 \\
\hline $\begin{array}{l}\text { Currency Identification } \\
\text { Accuracy }\end{array}$ & .109 & .805 & .180 & .129 & .123 \\
\hline Convenience of purchase & -.039 & .04 & .336 & .122 & .767 \\
\hline Convenience of payment & .105 & .161 & .077 & .126 & .696 \\
\hline Flexibility of settlement & .292 & .023 & .003 & .055 & .706 \\
\hline
\end{tabular}

a. Extraction method: principal component

Finally, the revised TVM user experience evaluation model was shown in Figure II.

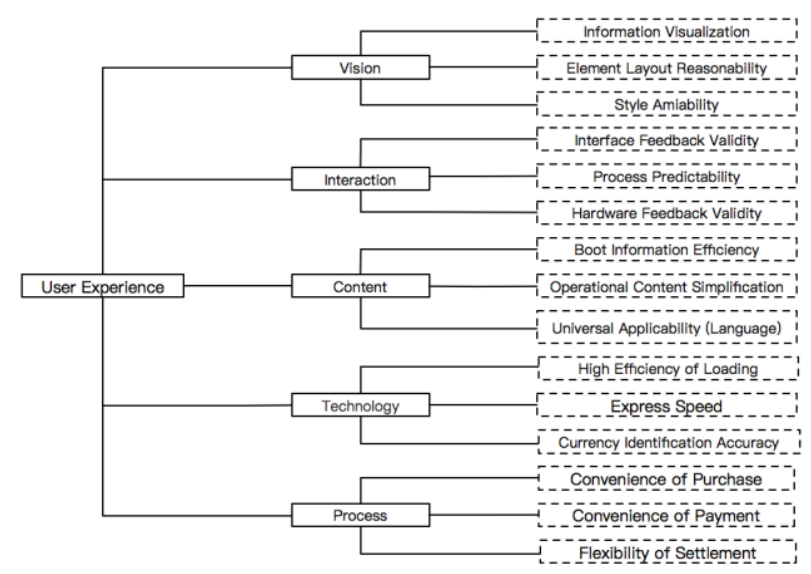

FIGURE II. REVISED TVM USER EXPERIENCE EVALUATION MODEL

\section{A TVM AVAILABILITY EVALUATION BASED ON AHP- GRA}

\section{A. TVM Evaluates Quantitative indicators}

The four groups of TVM schemes were quantitatively evaluated according to the available evaluation indexes. The 50 users in Beijing and Tokyo are studied by using the questionnaire survey and the task experiment design method. Select users with complete information of age, trial frequency, and nationality. The qualitative indexes include the grade of excellent, good, medium, poor and inferior, and the corresponding membership degree is $0.9,0.7,0.5,0.3$ and 0.1 . The scheme evaluates value are showed in Table II.

TABLE II. TVM QUANTITY INDEX

\begin{tabular}{|c|c|c|c|c|}
\hline \multirow[b]{2}{*}{ Element } & \multicolumn{4}{|c|}{ Scheme } \\
\hline & $\begin{array}{c}D_{1} \\
B J- \\
L 4\end{array}$ & $\begin{array}{c}D_{2} \\
B J- \\
L 13\end{array}$ & $\begin{array}{c}D_{3} \\
T Y O- \\
J R\end{array}$ & $\begin{array}{c}\mathrm{D}_{4} \\
\mathrm{TYO}- \\
\mathrm{M}\end{array}$ \\
\hline Information Visualization & 0.7 & 0.7 & 0.9 & 0.9 \\
\hline Element Layout Reasonability & 0.7 & 0.5 & 0.9 & 0.9 \\
\hline Style Amiability & 0.9 & 0.9 & 0.5 & 0.5 \\
\hline Interface Feedback Validity & 0.9 & 0.7 & 0.9 & 0.9 \\
\hline Process Predictability & 0.9 & 0.7 & 0.9 & 0.9 \\
\hline Hardware Feedback Validity & 0.7 & 0.5 & 0.9 & 0.9 \\
\hline Boot Information Efficiency & 0.9 & 0.7 & 0.7 & 0.9 \\
\hline Operational Content Simplification & 0.7 & 0.7 & 0.9 & 0.9 \\
\hline Universal Applicability (Language) & 2 & 2 & 4 & 7 \\
\hline High Efficiency of Loading & 0.7 & 0.5 & 0.9 & 0.9 \\
\hline Express Speed (time / s) & 2 & 3 & 3 & 2 \\
\hline Currency Identification Accuracy & 0.5 & 0.5 & 0.9 & 0.9 \\
\hline $\begin{array}{c}\text { Convenience of purchase(Types of } \\
\text { Ticket) }\end{array}$ & 2 & 1 & 5 & 3 \\
\hline Convenience of payment & 0.7 & 0.7 & 0.9 & 0.9 \\
\hline Flexibility of settlement & 1 & 1 & 2 & 2 \\
\hline
\end{tabular}

\section{B. TVM User Experience Evaluation Based on AHP - GRA}

Weight vector setup based on the AHP. Establish and optimize the TVM scheme based on user experience evaluation model, and divide the hierarchy into target layer $\mathrm{A}$, criterion layer B, evaluation index layer $\mathrm{C}$ and plan D according to AHP. The A-level is best for the user experience and it is the overall 
target layer; The five criteria of the $\mathrm{B}$ layer $\mathrm{B}_{1}, \mathrm{~B}_{2} \ldots \mathrm{B}_{5}$ includes five evaluations dimensional: visual, interaction, content, technology, and purchase processes; The $\mathrm{C}$ layer evaluates 15 indicators of the experience quality of these programs; The D layer includes four TVM schemes, Beijing Line 4, Beijing Line 13, Tokyo JR and Tokyo Metro. A hierarchy model diagram can be shown such as Figure III [5].

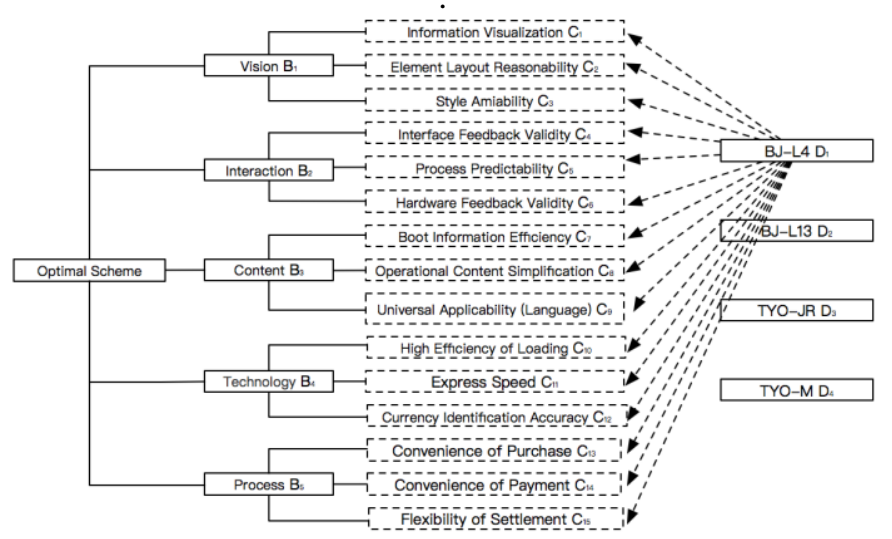

FIGURE III. TVM HIERARCHY MODEL DIAGRAM

TABLE III. WEIGHT SORTING LIST OF LEVEL C

\begin{tabular}{|c|c|c|c|c|c|c|}
\hline \multirow{2}{*}{ Level } & $\boldsymbol{B 1}$ & $\boldsymbol{B 2}$ & $\boldsymbol{B 3}$ & $\boldsymbol{B 4}$ & $\boldsymbol{B 5}$ & $\begin{array}{c}\text { Level C } \\
\text { Total weight } \\
\text { sorting }\end{array}$ \\
\hline $\mathrm{C}_{1}$ & 0.2312 & 0.1457 & 0.2091 & 0.2587 & 0.1553 & \\
\hline $\mathrm{C}_{2}$ & 0.4885 & 0 & 0 & 0 & 0 & 0.0690 \\
\hline $\mathrm{C}_{3}$ & 0.2132 & 0 & 0 & 0 & 0 & 0.1457 \\
\hline $\mathrm{C}_{4}$ & 0 & 0.2583 & 0 & 0 & 0 & 0.0376 \\
\hline $\mathrm{C}_{5}$ & 0 & 0.1047 & 0 & 0 & 0 & 0.0153 \\
\hline $\mathrm{C}_{6}$ & 0 & 0.637 & 0 & 0 & 0 & 0.0928 \\
\hline $\mathrm{C}_{7}$ & 0 & 0 & 0.3196 & 0 & 0 & 0.0668 \\
\hline $\mathrm{C}_{8}$ & 0 & 0 & 0.5884 & 0 & 0 & 0.1230 \\
\hline $\mathrm{C}_{9}$ & 0 & 0 & 0.122 & 0 & 0 & 0.0255 \\
\hline $\mathrm{C}_{10}$ & 0 & 0 & 0 & 0.3587 & 0 & 0.0928 \\
\hline $\mathrm{C}_{11}$ & 0 & 0 & 0 & 0.2382 & 0 & 0.0616 \\
\hline $\mathrm{C}_{12}$ & 0 & 0 & 0 & 0.4031 & 0 & 0.1043 \\
\hline $\mathrm{C}_{13}$ & 0 & 0 & 0 & 0 & 0.427 & 0.0663 \\
\hline $\mathrm{C}_{14}$ & 0 & 0 & 0 & 0 & 0.3125 & 0.0485 \\
\hline $\mathrm{C}_{15}$ & 0 & 0 & 0 & 0 & 0.2605 & 0.0405 \\
\hline
\end{tabular}

In this paper, we invite three experts from different fields to judge and construct the nine scale comparison judgment matrix. To order hierarchy in a single level and the whole system, we use the method of row and normalization. Make the sum of each row of the judging matrix and normalize the sum vector. Image the judging matrix as:

$$
\mathrm{A}=\left[\begin{array}{cccc}
a_{11} & a_{12} & \ldots & a_{1 n} \\
a_{21} & a_{22} & \ldots & a_{2 n} \\
\ldots & \ldots . & \ldots & \ldots \\
a_{n 1} & a_{n 2} & \ldots & a_{n \times n}
\end{array}\right]=\left\{a_{i j}\right\}_{n \times n}
$$

According to the row sum $\mathrm{Vi}=\sum_{j=1}^{n} a i \mathrm{j},(i=1,2, \ldots . n)$, obtain vector $\mathrm{W}=\left(\mathrm{v}_{1}, \mathrm{~V}_{2}, \ldots, \mathrm{v}_{\mathrm{n}}\right)^{T}$, and the vector by normalizing $\mathrm{W}=\left(\mathrm{w}_{1}, \mathrm{w}_{2}, \ldots, \mathrm{w}_{\mathrm{n}}\right)^{T}, \mathrm{~W}_{\mathrm{i}}$ is the priority for hierarchical ordering, namely, the weight of elements. The vector of the judgment matrix can be obtained by computing and the consistent check of the judgment matrix is needed. When the consistency index functions of the six judgment matrix are less than 0.10 , we can judge that the judgment matrix has a satisfactory consistency.
The Weight calculation by each level of A and B has been shown in Table III.

From Table III we can get weight allocation vector $\mathrm{W}$ :

$\mathrm{W}=(0.0690,0.1457,0.1041,0.0376,0.0153,0.0928,0.0668,0$. $1230,0.0255,0.0929,0.0616,0.1043,0.0663,0.0485,0.0405)^{\mathrm{T}}$

For the multi-objective problem, image a system is composed of $\mathrm{N}$ alternative, $\mathrm{X}=\left\{\mathrm{X}_{1}, \mathrm{X}_{2} \ldots, \mathrm{X}_{\mathrm{n}}\right\}^{T}$, each solution has an index set which is composed of $M$ evaluation index of evaluation scheme to evaluate. where $\mathrm{X}$ is the $\mathrm{M}$ index raw data the solution I, namely $\mathrm{X}$ expresses the $\mathrm{J}$ parameter values, and we can get the index eigenvector matrix $X$ of the $n$ plan [6].

Grey advantage analysis lies in the reasonable identifying reference solution, so according to the best part in each index of the plan, we can determine the virtual ideal scheme $\mathrm{X}_{0}$, and the index eigenvector matrix $\overline{\mathrm{X}}$ composed with $(\mathrm{N}+1)$ plan based on the superior quality principle. The index eigenvector matrix $\bar{X}$ should be changed into the standardized matrix $S$ because of the need to remove their effect on the outcome for their different dimension. The formula is as follows:

$$
\mathrm{S}_{\mathrm{ij}}=\frac{S_{i j}}{X_{j}^{o}} \text { or } \mathrm{S}_{\mathrm{ij}}=\frac{X_{i j}}{\max \left\{X_{i j}\right\}}
$$

The normalized matrix of $\mathrm{S}$ is:

$$
\mathrm{S}=\left[\begin{array}{c}
S_{0} \\
S_{1} \\
S_{2} \\
\ldots \\
S_{n}
\end{array}\right]=\left[\begin{array}{cccc}
1 & 1 & \ldots & 1 \\
S_{11} & S_{12} & \ldots & S_{1 m} \\
S_{21} & S_{22} & \ldots & S_{2 m} \\
\ldots & \ldots & \ldots & \ldots \\
S_{n 1} & S_{n 2} & \ldots & S_{n m}
\end{array}\right]
$$

As $S_{0}$ is converted, its optimal value is 1 . Make the processed optimal index set $S_{0}$ as reference data column, the normalized scheme index as a comparative sequence. The correlation coefficient $S$ element of the decision matrix $S_{i}$ in the undecided matrix Xi can be determined by equation (2). $S_{\mathrm{ij}}$ is the correlation coefficient in the $\mathrm{J}$ factor of the $\mathrm{S}_{0} . \rho$ is the distinguish coefficient of 0.5 , and the correlation coefficient matrix $\mathrm{E}$ can be obtained.

$$
\begin{gathered}
\xi_{\mathrm{ij}}=\frac{\operatorname{Min}_{i} \operatorname{Min}_{j}\left|S_{j}^{i}-S_{i j}\right|+\rho \operatorname{Min}_{i} \operatorname{Min}_{j}\left|S_{j}^{0}-S_{i j}\right|}{\left|S_{j}^{i}-S_{i j}\right|+\rho \operatorname{Min}_{i} \operatorname{Min}_{j}\left|S_{j}^{0}-S_{i j}\right|} \\
\mathrm{E}=\left[\begin{array}{cccc}
\xi_{11} & \xi_{12} & \ldots & \xi_{1 m} \\
\xi_{21} & \xi_{22} & \ldots & \xi_{2 m} \\
\ldots & \ldots & \ldots & \ldots \\
\xi_{n 1} & \xi_{n 2} & \ldots & \xi_{n m}
\end{array}\right]
\end{gathered}
$$

According to the weighted vector $\mathrm{W}$ and the index correlation coefficient matrix $\mathrm{E}$, the integrated evaluation matrix $\mathrm{R}$ is:

$$
\mathrm{R}=\mathrm{E} * \mathrm{~W}
$$

In accordance with the above principles, the evaluation index value of the ideal solution $\mathrm{D}_{0}$ is obtained according to the TVM quantitative value. As shown in Table II, the evaluation and 
judging normalization matrix $S$ of the various solutions can be obtained by introducing the data.

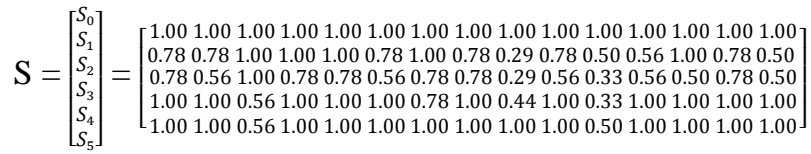

The coefficient of correlation can be obtained by the matrix $\mathrm{S}$ and the resolution coefficient $\rho$ :

$$
\xi_{\mathrm{ij}}=\frac{0.145}{\left(S_{j}^{i}-S_{i j}\right)+0.145}
$$

Based on the correlation coefficient matrix $\mathrm{E}$ and the index weight vector $\mathrm{W}$, we can obtain the integrated evaluation matrix $\mathrm{R}=\left[\begin{array}{llll}0.7334 & 0.6321 & 0.9092 & 0.9475\end{array}\right]$ and the comprehensive correlation of the 4 TVM schemes are shown in Table IV.

TABLE IV. COMPREHENSIVE CORRELATION DEGREE

\begin{tabular}{|c|c|c|c|c|}
\hline Scheme & $\boldsymbol{B J}-\boldsymbol{L A}$ & $\boldsymbol{B J}-\boldsymbol{L 1 3}$ & $\boldsymbol{T Y O}-\boldsymbol{J R}$ & $\boldsymbol{T Y O}-\boldsymbol{M}$ \\
\hline $\begin{array}{c}\text { Comprehensive } \\
\text { correlation degree r }\end{array}$ & 0.7334 & 0.6321 & 0.9092 & 0.9475 \\
\hline
\end{tabular}

From Table IV, the integrated correlation degree $\mathrm{D}_{4}>\mathrm{D}_{3}>$ $\mathrm{D}_{1}>\mathrm{D}_{2}$. In the market, TVM D $\mathrm{D}_{4}$ is the superior plan of humancomputer interaction.

\section{OPTIMIZATION SUGGESTION OF THE TVM SOLUTION BASED ON HUMAN-COMPUTER INTERACTION}

According to the index weight of the guideline layer, the technical elements and visual elements of TVM exert an important effect on the interaction quality. In these two elements, a reasonable element layout, a high speed loading, and an accurate currency identification make a greater part. The layout of different functional areas should be arranged according to the user's cognitive level and the operation process so as to ensure the fluency of the use. And loading speed and currency recognition accuracy will affect the users time in the overall operation process. If the use requirement or recognition time fail to be satisfied, the quality of human-computer interaction will be greatly reduced.

From the evaluation quantitative index of the four groups' TVM schemes, it can be seen that the experience quality of the overall TVM user is a bit weak than that of Japan, and the main factors include the lack of hardware technology breakthroughs such as currency recognition and settlement which affect the length of operating time and efficiency. On the other hand, in the visual information presentation, it is advisable to make classify optimization, increase the initials navigation for different sites, which will make users find the sites quickly in the case of having not clear line. Simplify the interactive process, and make order operation according to the user's mental model from choosing routes, payment to ticket drawing to avoid the effect of cross flow on the user experience.

\section{REFERENCES}

[1] Yunchao Yang, Application and discussion on AFC system of urban rail Transport[D]. Southwest Jiaotong University.

[2] Rat, Hans. The fall and rise of urban rail transport[J]. International Railway Journal,2011,513:
[3] Maguire M C, A Review of User - Interface Design Guidelines for Public Information Kiosk Systems [J]. International Journal of Human Computer Studies, 1991. $50: 263$ - 286

[4] Lee H , Grey B, 2011 North American Self - Service Kiosks [J]. IHL Group, 2011

[5] Saaty T L. Inner and outer Dependence in the Analytic Hierachy Process: The Supermatric and Superhierarchy [A], Proceeding of the $2^{\text {nd }}$ ISAHP[C], Pittsburgh, PA, 1991

[6] Naseer Ahmad,Shahid Kamal,Zulfiqar Ali Raza,Tanveer Hussain,Faiza Anwar. Multi-response optimization in the development of oleohydrophobic cotton fabric using Taguchi based grey relational analysis[J]. Applied Surface Science, 2016. 